\title{
Radiation-Induced Myelitis: Initial and Follow-Up MRI and Clinical Features in Patients at a Single Tertiary Care Institution during 20 Years
}

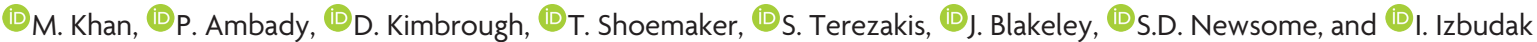

\begin{abstract}
SUMMARY: Myelitis is a rare complication of radiation exposure to the spinal cord and is often a diagnosis of exclusion. A retrospective review of clinical records and serial imaging was performed to identify subjects with documented myelitis and a history of prior radiation. Eleven patients fulfilled the inclusion criteria. All patients had longitudinally extensive cord involvement with homogeneous precontrast $\mathrm{T} 7$ hyperintense signal in the adjacent vertebrae, corresponding to the radiation field. $\mathrm{T} 2$ signal abnormalities involving the central two-thirds of the cord were seen in 6/11 patients (55\%). The degree of cord expansion and contrast enhancement was variable but was seen in $6(54 \%)$ and 5 (45\%) patients, respectively. On follow-up, 2 patients developed cord atrophy, while complete resolution was noted in 1. Clinical improvement was noted in 5 patients, with symptom progression in 2 patients. Our results suggest that radiation myelitis is neither universally progressive nor permanent, and some radiographic and clinical improvement may occur.
\end{abstract}

ABBREVIATION: $R M=$ radiation myelitis

$\mathbf{R}$ diation myelitis (RM) is a rare-but-dreaded complication of radiation exposure to the spinal cord. This feared complication often limits volume, dose per fraction, and field of radiation therapy. ${ }^{1}$ Most centers limit the total dose to the cord to $<45 \mathrm{~Gy}$ in 1.8- to 2-Gy fractions to minimize this risk. ${ }^{2-6}$ Diagnosis of delayed RM is difficult and often a diagnosis of exclusion. More common causes of transverse myelitis (partial and/or longitudinally extensive), including demyelinating diseases (multiple sclerosis, neuromyelitis optica), rheumatoid diseases (lupus, Sjögren syndrome), and infectious etiologies (viral, bacterial), as well as primary and metastatic tumors, should be considered. Occasionally, paraneoplastic syndromes can also present with myelitis. ${ }^{7}$ Although very rare, ruling out recurrent or metastatic tumors is a major concern in the context of a prior history of malignancies. ${ }^{8-10}$ However, it is important to keep RM in the differential

Received March 11, 2018; accepted March 16.

From the Brain Cancer Program (P.A., J.B., S.T.), Department of Radiation Oncology (S.T.), Sidney Kimmel Comprehensive Cancer Center at Johns Hopkins; Division of Neuroimmunology and Neuroinfectious Diseases, Department of Neurology (D.K. T.S., S.D.N.); and Division of Neuroradiology, Russell H. Morgan Department of Radiology (M.K., I.I.), Johns Hopkins University School of Medicine, Baltimore, Maryland; Neuro-Oncology Branch (P.A.), National Cancer Institute, Bethesda, Maryland; and Blood Brain Barrier and Neuro-Oncology Program (P.A.), Oregon Health and Science University, Portland, Oregon.

Majid Khan and Prakash Ambady contributed equally to this work.

Please address correspondence to Izlem Izbudak, MD, Department of Radiology, Johns Hopkins Hospital, Phipps B112, 600 N Wolfe St, Baltimore, MD 21287; e-mail: iizbudal@jhmi.edu

http://dx.doi.org/10.3174/ajnr.A5671

diagnosis, especially when patients have a history of prior radiation therapy. Prompt diagnosis of RM is difficult because symptoms can vary, and onset (latent period) can range from a few months to several years following radiation exposure. ${ }^{11,12}$

Contrast-enhanced MR imaging is frequently used as a diagnostic tool to help develop a differential diagnosis. Frequently described MR imaging characteristics of RM include spinal cord expansion, atrophy, hyperintense signal changes on T2-weighted images, and contrast enhancement. ${ }^{13-19}$ However, these imaging findings are nonspecific and can vary depending on the timing of MR imaging with respect to radiation exposure. ${ }^{14,19}$ This study aims to describe the clinical features and MR imaging characteristics of delayed radiation-induced myelitis at our institution in past 2 decades.

\section{Case Series}

The institutional review board at Johns Hopkins Hospital approved this retrospective study and waived patient informed consent. A radiology departmental data base of MR imaging spine studies conducted between 1993 and 2013 was searched using the keywords "myelitis" and "radiation." A neuro-oncologist (P.A.) and a neuroimmunologist (D.K.), both in their second year of their respective fellowships, reviewed clinical records and identified patients with a history of radiation therapy and neurologic symptoms localized to the spinal cord as the reason for spine imaging. Two neuroradiologists (I.I. and M.K.) with 10 years of experience independently reviewed all relevant MR imaging findings.

The MR imaging examinations were performed with either 1.5T or 3T magnets from different manufacturers: 1.5 Intera 


\begin{tabular}{|c|c|}
\hline $\begin{array}{c}\text { Radiology database search: } \\
\text { MRI reports with search terms Myelitis } \\
\text { and/or radiation in report: } \\
15,935 \text { reports }\end{array}$ & \\
\hline $\begin{array}{c}\downarrow \\
\text { MRI Reports suggestive of or confirming } \\
\text { Radiologic evidence of transverse myelitis: } \\
550 \text { reports }\end{array}$ & $\begin{array}{l}\quad \text { Excluded } \\
\text { 1. Primary or metastatic } \\
\text { tumor involving the spinal } \\
\text { cord }\end{array}$ \\
\hline$\downarrow$ & 2. Clinical history and \\
\hline$\sqrt{ }$ & nutritional \\
\hline $\begin{array}{c}\text { Included } \\
\text { Confirmed history of prior radiation and } \\
\text { fulfilled inclusion criteria: } \\
11 \text { patients } \\
\text { (11 patient with MRI images, } 10 \text { patients } \\
\text { complete clinical history) }\end{array}$ & $\begin{array}{l}\text { deficiencies (B12, Copper), } \\
\text { multiple sclerosis, } \\
\text { neuromyleitis optica, } \\
\text { rheumatoid or infectious } \\
\text { etiology }\end{array}$ \\
\hline
\end{tabular}

FIG 1. Study schema describes the method used to identify the patients in this series. It also highlights the rarity of the occurrence of radiation myelitis.

\section{Table 1: Clinical course of myelopathy}

\begin{tabular}{|c|c|}
\hline Symptoms at presentation ${ }^{a}$ & $\begin{array}{l}\text { Paresthesia lower limbs: } 6 / 10(60 \%) \\
\text { Pain (back and legs): } 5 / 10(50 \%) \\
\text { Lower extremity motor weakness: } \\
\quad 7 / 10 \text { (70\%) } \\
\text { Urinary incontinence: } 4 / 10(40 \%) \\
\text { Bowel incontinence: } 2 / 10(20 \%)\end{array}$ \\
\hline Treatment received & $\begin{array}{l}\text { Steroids: } 9 \\
\text { Ivlg: } 1 \\
\text { Hyperbaric oxygen: } 2 \\
\text { Plasmapheresis: } 2 \\
\text { Bevacizumab (Avastin): } 1\end{array}$ \\
\hline $\begin{array}{l}\text { Mean duration of clinical } \\
\text { follow-up (mo) }\end{array}$ & 22 (range: 4-162) \\
\hline $\begin{array}{l}\text { Clinical course on } \\
\text { follow-up (available in } 7 \\
\text { patients) }\end{array}$ & $\begin{array}{l}\text { Improved with some sequelae: } 5 \\
\text { Progressive: } 2 \\
\text { Resolved: } 0\end{array}$ \\
\hline
\end{tabular}

Note:- - vlg indicates intravenous immunoglobulin.

${ }^{a}$ Detailed clinical examination was not available for 1 patient. Hence, only 10 patients were included for evaluation of the clinical course.

Table 2: Demographics of 11 subjects included in the study

\begin{tabular}{|c|c|}
\hline Attributes & Median (Range) \\
\hline Sex & 6 males, 5 females \\
\hline Median age (yr) & $33(11-60)$ \\
\hline $\begin{array}{l}\text { Primary malignancy (No. of } \\
\text { patients) }\end{array}$ & $\begin{array}{l}\text { 1) Recurrent Hodgkin lymphoma: } 5 \\
\text { 2) Hodgkin lymphoma: } 1 \\
\text { 3) Gastric carcinoma: } 1 \\
\text { 4) Acute lymphocytic lymphoma: } 1 \\
\text { 5) Brain stem glioma: } 1 \\
\text { 6) Medulloblastoma: } 1 \\
\text { 7) Recurrent multiple myeloma: } 1\end{array}$ \\
\hline $\begin{array}{l}\text { Median time to symptom } \\
\text { onset from RT (mo) }\end{array}$ & $17(2-194)$ \\
\hline $\begin{array}{l}\text { Median delay in diagnosis } \\
\text { from symptom onset (mo) }\end{array}$ & $6(0-14)$ \\
\hline
\end{tabular}

(Philips Healthcare, Best, the Netherlands), 1.5T Signa (GE Healthcare, Milwaukee, Wisconsin), Aera 1.5T, and Skyra 3T (Siemens, Erlangen, Germany), with routine spine MR imaging including sagittal T1-weighted and sagittal STIR imaging. Axial and sagittal T1-weighted images after intravenous gadolinium contrast administration $(0.1 \mathrm{~mL} / \mathrm{kg})$ were also acquired. The scan parameters were almost identical between different $1.5 \mathrm{~T}$ and $3 \mathrm{~T}$ scanners.

The inclusion criterion for the study was only patients with cord signal changes in the field of radiation with pertinent neurologic symptoms attributed to the involved spinal segments. There was no restriction to the age at presentation or duration since radiation exposure occurred. Exclusion criteria were patients with a documented clinical diagnosis of neurologic symptomatology such as primary or metastatic spinal tumors, patients having undergone radiation for spinal cord tumors, multiple sclerosis, neuromyelitis optica, rheumatoid diseases, infectious etiologies, and/or vitamin B12/copper deficiency (Fig 1).

Eleven patients fulfilled the criteria for final analysis. One patient included only in the imaging review was referred to our institution for a second opinion, and only a single brief clinical note was available, with symptom onset and clinical follow-up not available for this patient. Therefore, we did not include this patient in the analysis of clinical symptoms (Table 1). Six males and 5 females (mean age, 33 years; range, 11-60 years) were identified (Table 2). CSF analysis findings were nonspecific, and cytology was negative for malignancies in all.

All 11 patients received radiation therapy for malignancies not directly involving the spine, with segments of the spinal cord developing myelitis included within the radiation field. Details of individual cases are summarized in Table 3. Six (55\%) patients had prior chemotherapy. The median time from radiation therapy to symptom onset (latent period) was 17 months (range, 2-194 months). We noted a further median delay of 6 months (range, 0-14 months) from symptom onset to confirmation of clinical diagnosis. Sixty percent of patients reported lower leg paresthesia, 70\% reported lower extremity motor weakness, and 50\% reported back pain with radiculopathy at presentation. Four patients reported urinary and 2 reported bowel incontinence at presentation. Steroids were the most frequent therapy given at presentation. Among 7 patients with clinical follow-up data (mean follow-up, 22 months; range, 4-162 months), 5 reported some improvement in clinical symptoms, while 2 were noted to have progressive symptoms (wheelchair-bound).

The mean duration from symptom onset to the first MR imaging was around 6 months (range, $0-41$ months). Imaging findings summarized in Table 4 revealed that all 11 patients had at least $1 \mathrm{MR}$ imaging that demonstrated cervical and/or thoracic cord lesions in a longitudinally extensive pattern (Fig 2), with T1 hyperintensity in the adjacent vertebrae included in the field of radiation (Fig 1A). T2 signal abnormalities predominantly involved the central cord on axial images. Involvement of the central two-thirds of the axial cord was noted in 4, the central and posterior cord was involved in 1, and the entire circumference of the axial cord was involved in 5 patients at their initial MR imaging (Fig 3). Cord expansion was seen in 6 patients, with promi- 
Table 3: Patient demographics and oncology treatment history

\begin{tabular}{|c|c|c|c|c|c|}
\hline Patient & $\begin{array}{l}\text { Age } \\
\text { (yr) }\end{array}$ & Cancer Type & $\begin{array}{l}\text { Prior } \\
\text { Chemotherapy }\end{array}$ & $\begin{array}{l}\text { Prior } \\
\text { Chemotherapy } \\
\text { Regimen }\end{array}$ & Adjuvant Chemotherapy \\
\hline 1 & 33 & Recurrent Hodgkin lymphoma & Yes & $A B V D$ & $\begin{array}{l}\text { ICE followed by } \\
\text { cyclophosphamide (Cytoxan) and busulfan } \\
\text { Autologous bone marrow transplant }\end{array}$ \\
\hline 2 & 32 & Recurrent Hodgkin lymphoma & Yes & $\mathrm{CHOP} / \mathrm{ABVD}$ & $\begin{array}{l}\text { Ara-C, vincristine, cisplatin } \\
\text { Danazol }\end{array}$ \\
\hline 3 & 11 & Brain stem medulloblastoma & No & - & $\begin{array}{l}\text { Vincristine, VP-16, carboplatin } \\
\text { CCNU, cisplatin }\end{array}$ \\
\hline 4 & 60 & Recurrent gastric adenocarcinoma (stage IV) & No & - & 5-FU, leucovorin \\
\hline 5 & 42 & Refractory acute lymphocytic leukemia & Yes & $\begin{array}{l}\text { Hyper-CVAD } \\
\text { Methotrexate } \\
\text { 6-Mercaptopurine }\end{array}$ & $\begin{array}{l}\text { Intrathecal cytarabine } \\
\text { Autologous bone marrow transplant }\end{array}$ \\
\hline 6 & 41 & Hodgkin lymphoma & No & - & No \\
\hline 7 & 29 & Brain stem glioma & No & - & TMZ \\
\hline 8 & 28 & Recurrent Hodgkin lymphoma & Yes & $A B V D$ & $\begin{array}{l}\text { ICE followed by } \\
\text { cyclophosphamide and busulfan } \\
\text { Autologous bone marrow transplant }\end{array}$ \\
\hline 9 & 33 & Recurrent Hodgkin lymphoma & Yes & $A B V D$ & $\begin{array}{l}\text { ICE followed by } \\
\text { cyclophosphamide and busulfan } \\
\text { Brentuximab vedotin } \\
\text { Autologous bone marrow transplant }\end{array}$ \\
\hline 10 & 37 & Recurrent Hodgkin lymphoma & Yes & $A B V D$ & $\begin{array}{l}\text { ICE followed by } \\
\text { cyclophosphamide and busulfan } \\
\text { Autologous bone marrow transplant }\end{array}$ \\
\hline
\end{tabular}

Note:-ABVD indicates doxorubicin, bleomycin, vinblastine, dacarbazine; CHOP, cyclophosphamide, doxorubicin hydrochloride, vincristine, prednisone; Hyper-CVAD, cyclophosphamide, vincristine, doxorubicin, and dexamethasone; TMZ, temozolomide; CCNU, lomustine; ICE, ifosfamide, carboplatin, etoposide chemotherapy protocol; Vp-16, etoposide phosphate.

\begin{tabular}{|c|c|}
\hline $\begin{array}{c}\text { Mean time from symptom } \\
\text { onset to first MRI (mo) }\end{array}$ & 6 (Range, 0-41) \\
\hline \multirow{4}{*}{$\begin{array}{l}\text { Level of longitudinally extensive } \\
\text { myelitis (No. of patients) (\%) }\end{array}$} & Cervical: 3 (27\%) \\
\hline & Thoracic: 5 (45\%) \\
\hline & Cervical and thoracic: 2 (18\%) \\
\hline & Entire spine: 1 (9\%) \\
\hline \multirow{6}{*}{$\begin{array}{l}\text { Level of vertebral } \mathrm{T} 1 \\
\text { hyperintensities } \\
\text { (No. of patients) (\%) }\end{array}$} & Cervical: 2 (18\%) \\
\hline & Cervical and thoracic: 3 (27\%) \\
\hline & Thoracic: $1(9 \%)$ \\
\hline & Thoracic and lumbar: $1(9 \%)$ \\
\hline & Entire spine: $2(18 \%)$ \\
\hline & No changes: 2 (18\%) \\
\hline \multirow{4}{*}{$\begin{array}{l}\text { Location of axial T2 changes } \\
\text { (No. of patients) (\%) }\end{array}$} & Central $(>2 / 3): 4(36 \%)$ \\
\hline & Central and posterior: $1(9 \%)$ \\
\hline & Entire cord: 5 (45\%) \\
\hline & Indeterminate: $1(9 \%)$ \\
\hline \multirow{3}{*}{$\begin{array}{l}\text { Cord expansion (No. of } \\
\text { patients) (\%) }\end{array}$} & Present: 6 (54\%) \\
\hline & Absent: $3(27 \%)$ \\
\hline & Indeterminate: 2 (18\%) \\
\hline \multirow{3}{*}{$\begin{array}{l}\text { Contrast enhancement (No. } \\
\text { of patients) (\%) }\end{array}$} & Enhancement present: $5(45 \%)$ \\
\hline & No enhancement: 5 (45\%) \\
\hline & Contrast not given: $1(9 \%)$ \\
\hline
\end{tabular}

nent expansion in 3 (as evidenced by a completely effaced thecal sac circumferentially on axial T2-weighted images), and mild expansion in 3 patients. Contrast enhancement was variable and was seen in $45 \%$ of cases. Follow-up MR imaging (Table 5) was available for $8(73 \%)$ patients (median, 14.5 months; range, 4-69 months). On follow-up MRIs, cord atrophy was noted in only 2 of 8 patients $(25 \%)$. Persistent T2 abnormalities in the cord were noted in 4 of $8(50 \%)$, while complete resolution of MR imaging findings was seen in 1 of 8 (12.5\%). Hemorrhagic changes were noted in 1 of $8(12.5 \%)$, with syringohydromyelia also noted in 1 patient (12.5\%).

\section{DISCUSSION}

Our report is relevant considering the rarity of RM (only 11 cases during 20 years at a tertiary care institution). Our report reinforces the long latent period and variable clinical and imaging findings in RM. ${ }^{11,13,17-21}$ Our study also reaffirms that the longitudinally extensive cord signal pattern corresponding to the radiation field and the additional demonstration of T1-weighted hyperintense marrow signal changes noted in vertebrae included in the radiation field were useful imaging findings in incorporating $\mathrm{RM}$ in the differential diagnosis. These imaging findings may draw the investigator's attention to the tissue alterations in the field of radiation, especially when there is a long latency before the development of symptoms or when radiation fields are not readily available and may give us helpful hints about the etiology of myelitis. ${ }^{22,23}$ Central aspect of spinal cord seemed to be predominantly involved because it contains spinal gray matter with myelinated tracts at the periphery and suggests a possible vascular etiology due to delayed regional vasculitis secondary to radiation rather than demyelination. ${ }^{24}$ Our study, like most prior studies, suggests that MR imaging findings including cord expansion and contrast enhancement are seen initially at presentation and tend to resolve on follow-up. In our cohort, cord expansion was seen in $55 \%$ of patients, while no cord expansion was seen in $27 \%$ at initial presentation, with contrast enhancement being variable in our cohort, indicating temporal variability in the blood-cord barrier permeability. Hemorrhagic changes in the cord were associated with the most severe case of RM.

Prior reports have suggested that RM is a progressive and permanent disease. ${ }^{11,25}$ However, $45 \%$ of our patients reported some improvement in their neurologic symptoms on follow-up. The mechanism of neurologic recovery is unclear but may be due to 

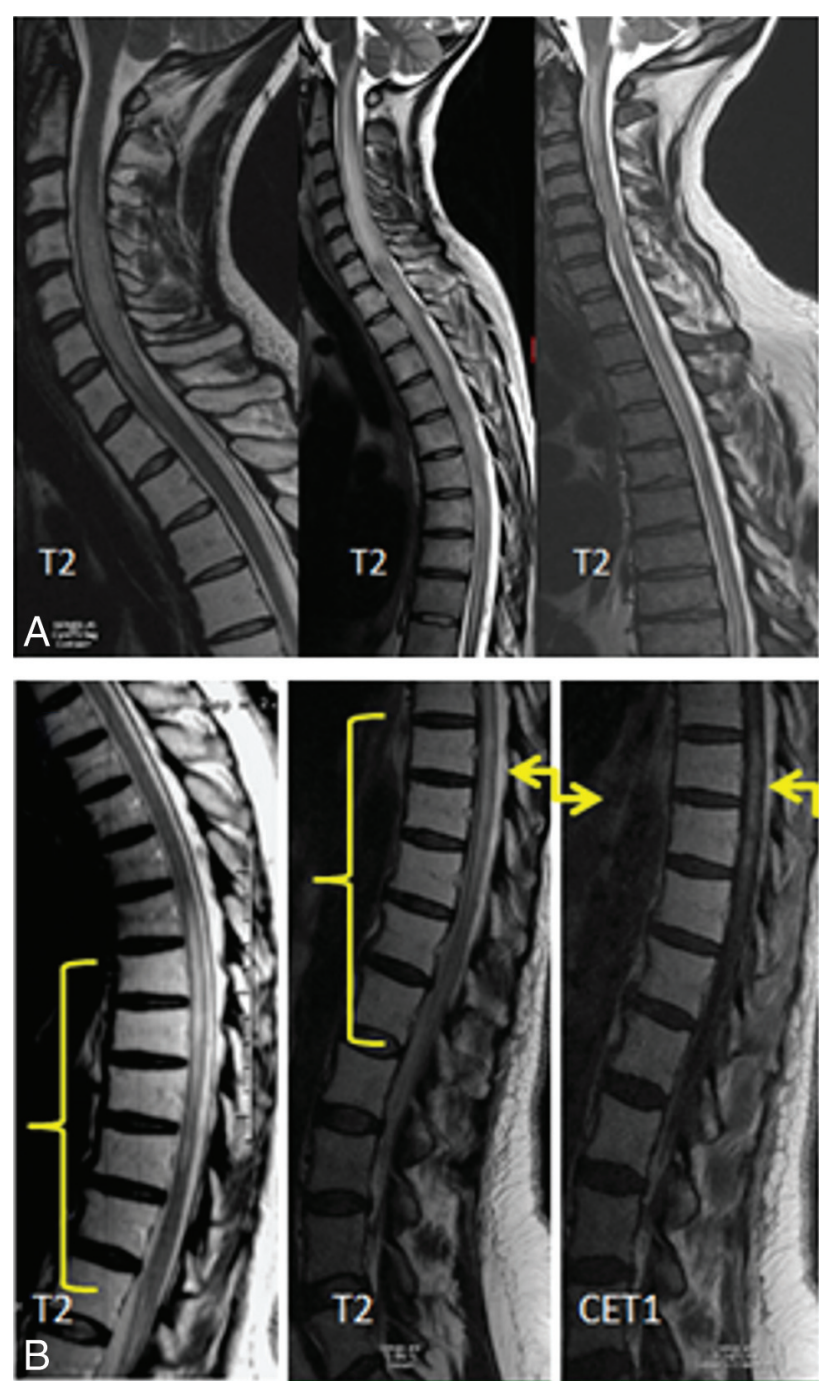

FIG 2. Longitudinally extensive myelitis. $A$, The cervical or thoracic cord or both were involved in all patients in a longitudinally extensive pattern. B, Maximum myelopathic changes (yellow arrows) correspond to the central field of radiation identified by apparent fatty vertebral bone marrow on T1-weighted images (yellow brackets).

resolution of cord edema and inflammation, which may manifest as cord expansion in the early phase. Other possible explanations for clinical improvement may include remyelination and revascularization associated with improvement in the MR imaging abnormalities as described in this report. Most patients in our cohort received steroids at presentation, while a smaller number received bevacizumab, immunoglobulin, plasmapheresis, or hyperbaric oxygen in addition to steroids. It is unclear whether the radiologic improvement in our series was due to these therapies or the natural history of this condition. Literature review suggests that some cases of RM may be steroid-responsive, while animal studies and case reports have demonstrated an anecdotal benefit with therapies such as hyperbaric oxygen and bevacizumab when used in the acute phase. ${ }^{25-27}$

The most important and concerning cause of myelopathy in a patient with cancer is still disease progression. ${ }^{28} \mathrm{RM}$ is a diagnosis of exclusion, and contrast-enhanced MR imaging is frequently used to help aide in this diagnosis and differentiate this entity from tumors or infections. The pathophysiology of radiation

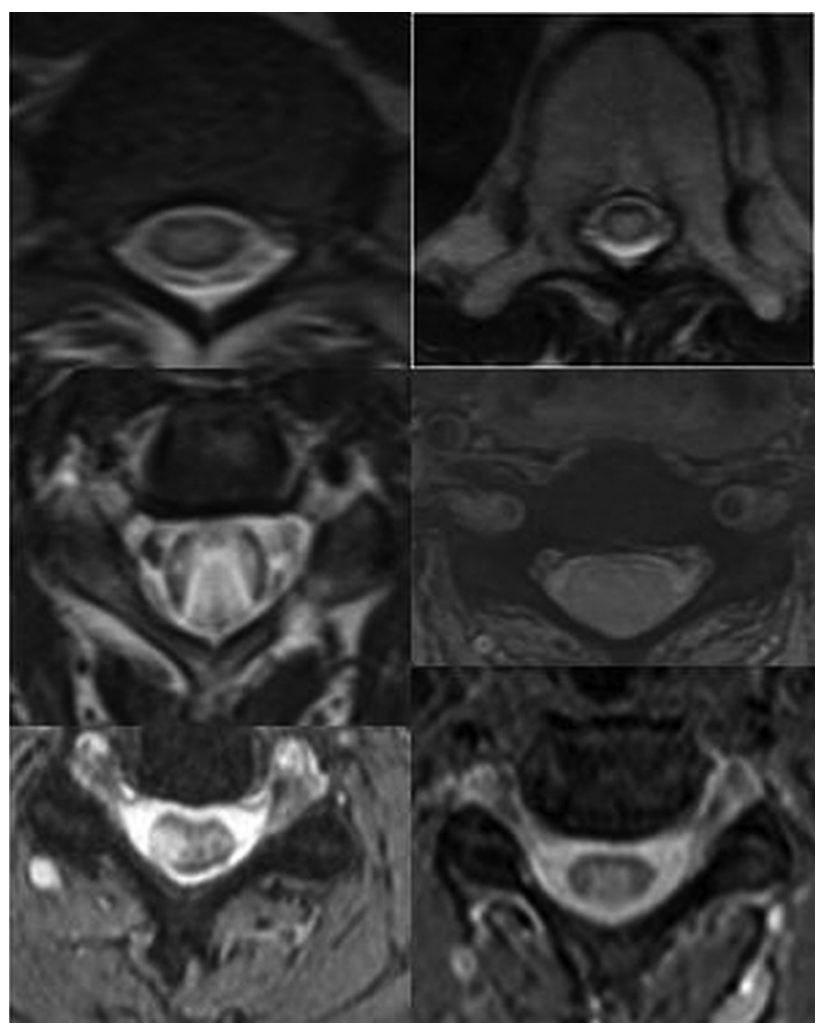

FIG 3. Central cord involvement. The central two-thirds of the cord on axial T2-weighted images was involved in 9 patients, and 1 patient presented with a small focal area of central and dorsal cord involvement.

\section{Table 5: Findings on follow-up spine MRI}

\begin{tabular}{ll}
\hline Radiographic follow-up & Yes: 8 \\
available & No: 3 \\
Median follow-up (mo) & $14.5(4-69)$ \\
Cord atrophy (No. of & Present: 2 (25\%) \\
patients) (\%) & Absent: 6 (75\%) \\
T2 findings (No. of & Decreased T2 abnormalities: 4 (50\%) \\
patients) (\%) & Resolved: 1 (12.5\%) \\
& Hemorrhagic changes: $1(12.5 \%)$ \\
& Syringohydromyelia: 1 (12.5\%) \\
& Persistent T2 abnormalities: 4 (50\%) \\
\hline
\end{tabular}

damage to the central nervous system is not well-defined, but oligodendrocytes and endothelial cells are considered major targets. ${ }^{28-32}$ It is believed that endothelial cells are sensitive to radiation, but the effect has a longer latency in contrast to the glia, which is less sensitive but has a shorter latency. ${ }^{20}$ Thus, early transient changes can be presumed to be due to demyelination, while more permanent changes are attributed to small-vessel ischemia with the extent of involvement dictating the severity and timing of symptoms. ${ }^{24}$ The resulting evolving changes in the microvasculature and blood-cord barrier permeability have been historically held responsible for the temporal variability of presentation and inconsistent enhancement with contrast agents. ${ }^{25}$

Another striking finding of this study is the high incidence of RM in patients with recurrent malignancies or patients who receive chemotherapy prior and/or concurrent with radiation. A cumulative radiation dose below $45 \mathrm{~Gy}$ in daily 1.8- to 2-Gy fractions is a widely accepted dose constraint for the spinal cord, ${ }^{2-6}$ and these dose constraints have certainly limited RM to a rare 


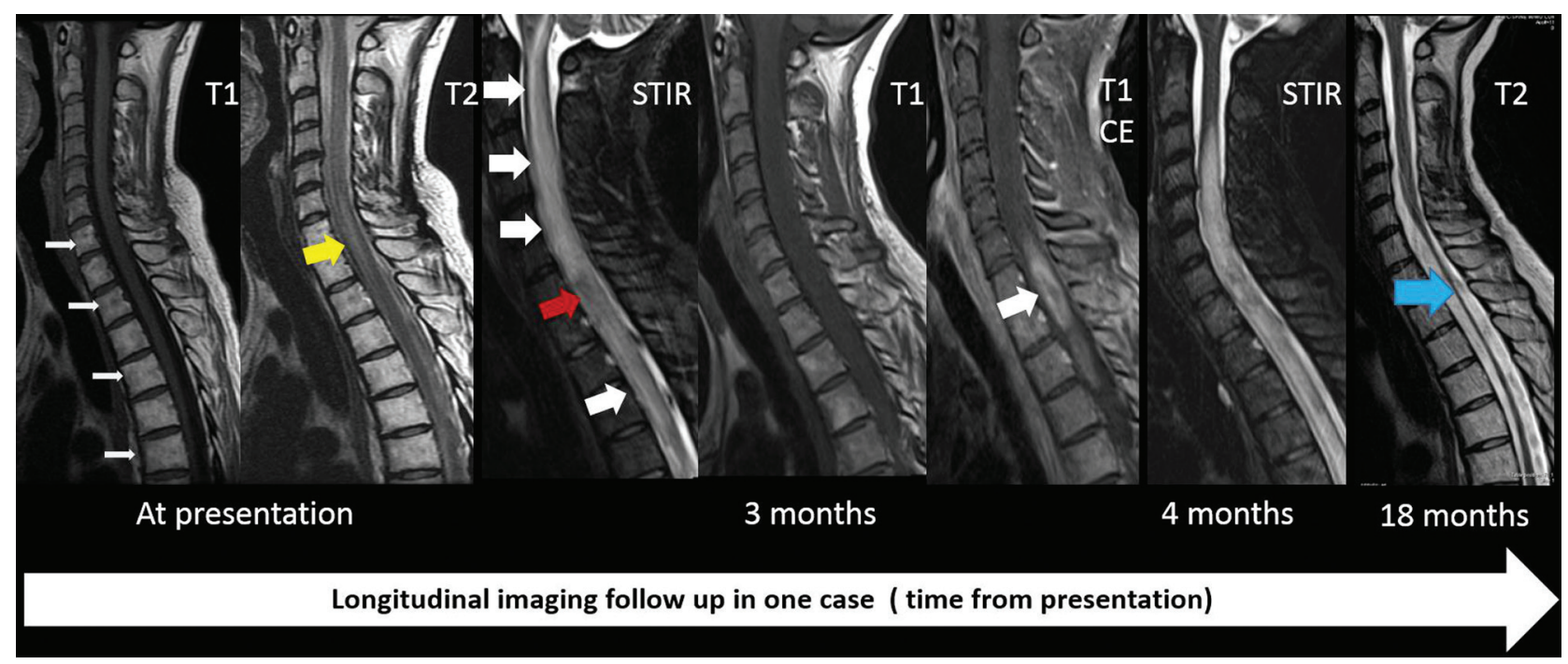

FIG 4. Sequential changes on imaging in a patient with severe radiation myelitis. Fatty bone marrow changes present with hyperintense $T 7$ signal involving C7 and the upper thoracic vertebrae on the first image (white arrows). Less extensive longitudinally extensive myelitis at the C7, T1, and T2 levels is noted on the T2-weighted image with hyperintense signal at presentation (yellow arrow). At 3 months, cord expansion and extensive T2/STIR hyperintense signal changes involving the cervical and upper thoracic cord are noted (white arrowhead) with contrast enhancement at the C7, T1, and T2 levels (single large white arrowhead). The patient was paraplegic with urinary and bowel incontinence. She was treated with a high dose of steroids. Follow-up images at 18 months show cord atrophy (blue arrow). She eventually was able to ambulate with a walker after extensive physical therapy. CE indicates contrast enhancement.

complication. However, there is renewed interest in better understanding the clinical features, imaging findings, and underlying pathophysiology due to the re-emergence of RM with the increasing role of stereotactic radiosurgery and re-irradiation. ${ }^{25}$ Our patients developed radiation myelitis even though they received a cumulative radiation dose well within the accepted tolerance limits for the spinal cord. Prior studies have indicated that tissue tolerance to radiation may be reduced with premedication with radiosensitizing chemotherapy. ${ }^{33-35}$ Most patients in our cohort were young (median age, 33 years), and this age may suggest that younger patients are at higher risk of developing RM, given the more intensive systemic therapy they generally receive.

This study suggests that there was a median delay of around 6 months before a firm diagnosis was made, highlighting the importance of time to correct diagnosis, with the start of and type of intervention possibly playing an important role in outcome. Prompt diagnosis may help avoid more invasive tests like biopsies.

Our study is unique because follow-up imaging and clinical history were available in most of our patients, and on follow-up, cord atrophy was seen in only $25 \%$ of our cases, which suggests that the timing of MR imaging after radiation may dictate the imaging findings. One of the interesting observations in this study is resolution or a decrease in T2 signal changes (Fig 4), affecting $12.5 \%$ and $50 \%$, respectively, on follow-up, especially because $\mathrm{RM}$ is thought to be irreversible and permanent. Although formal statistical analysis was not possible due to the rarity of occurrence and small sample size, our series suggests that clinical improvement may correlate well with imaging findings on longitudinal follow-up. Hemorrhagic changes, cord expansion, and contrast enhancement were variable and were noted in patients who were scanned early during the disease process, and tended to resolve on follow-up. This finding has not been well-reported, and our correlation with clinical history suggests that the extent of hemor- rhagic changes may dictate the severity of neurologic symptoms at presentation and disability at follow-up.

\section{Limitation}

We acknowledge that it is difficult to draw direct correlates between imaging findings and clinical outcomes because of the clinical data available being retrospective and issues related to recall bias due to the long latent period from symptom onset to diagnosis. Furthermore, patients were evaluated by a variety of providers (internists, medical oncologists, radiation oncologists, and neurologists) and the level of documentation varied between different specialties and clinical expertise of providers. Further studies should be performed to corroborate the findings of our study, including multicenter involvement to increase the sample size; however, the long-term follow-up and detailed clinical and radiologic data of this study are very informative.

Disclosures: Stephanie Terezakis—UNRELATED: Consultancy: L.E.K. Consulting; Em ployment: Johns Hopkins School of Medicine; Grants/Grants Pending: Elekta Instruments. Jaishri Blakeley—UNRELATED: Consultancy: AbbVie, Comments: through 2016 for 2 sessions of consultancy for a quality-of-life study. Izlem Izbudak—UNRELATED: Consultancy: Alexion Pharmaceuticals, Comments: neuromyelitis optica relapse adjudication committee MRI reads; Grants/Grants Pending: Siemens, Biogen, Comments: Siemens, DTI of the spinal cord prospective research grant; Biogen, MS PATHS scan-rescan brain MRI substudy. * Money paid to the institution.

\section{REFERENCES}

1. Jin JY, Huang Y, Brown SL, et al. Radiation dose-fractionation effects in spinal cord: comparison of animal and human data. J Radiat Oncol 2015;4:225-33 CrossRef Medline

2. Breit A. Radiation tolerance of the spinal cord. Int J Radiat Oncol Biol Phys 1989;16:675-78 Medline

3. Emami B, Lyman J, Brown A, et al. Tolerance of normal tissue to therapeutic irradiation. Int J Radiat Oncol Biol Phys 1991;21:109-22 Medline

4. Kirkpatrick JP, van der Kogel AJ, Schultheiss TE. Radiation dose- 
volume effects in the spinal cord. Int J Radiat Oncol Biol Phys 2010; 76:S42-49 CrossRef Medline

5. Martel MK, Eisbruch A, Lawrence TS, et al. Spinal cord dose from standard head and neck irradiation: implications for three-dimensional treatment planning. Radiother Oncol 1998;47:185-89 CrossRef Medline

6. Schultheiss TE. Spinal cord radiation "tolerance": doctrine versus data. Int J Radiat Oncol Biol Phys 1990;19:219-21 Medline

7. Dalmau J, Graus F, Rosenblum MK, et al. Anti-Hu-associated paraneoplastic encephalomyelitis/sensory neuronopathy: a clinical study of 71 patients. Medicine (Baltimore) 1992;71:59-72 CrossRef Medline

8. Chamberlain MC. Neoplastic myelopathies. Continuum (Minneap Minn) 2015;21(1 Spinal Cord Disorders):132-45 CrossRef Medline

9. Payer S, Mende KC, Westphal M, et al. Intramedullary spinal cord metastases: an increasingly common diagnosis. Neurosurg Focus 2015;39:E15 CrossRef Medline

10. Hrabalek L. Intramedullary spinal cord metastases: review of the literature. Biomed Pap Med Fac Univ Palacky Olomouc Czech Repub 2010;154:117-22 CrossRef Medline

11. Reagan TJ, Thomas JE, Colby MY Jr. Chronic progressive radiation myelopathy: its clinical aspects and differential diagnosis. JAMA 1968;203:106-10 Medline

12. Marcus RB Jr, Million RR. The incidence of myelitis after irradiation of the cervical spinal cord. Int J Radiat Oncol Biol Phys 1990;19:3-8 CrossRef Medline

13. Komachi H, Tsuchiya K, Ikeda M, et al. Radiation myelopathy: a clinicopathological study with special reference to correlation between MRI findings and neuropathology. J Neurol Sci 1995;132: 228-32 CrossRef Medline

14. Wang PY, Shen WC, Jan JS. Serial MRI changes in radiation myelopathy. Neuroradiology 1995;37:374-77 Medline

15. Michikawa M, Wada Y, Sano M, et al. Radiation myelopathy: significance of gadolinium-DTPA enhancement in the diagnosis. Neuroradiology 1991;33:286-89 CrossRef Medline

16. Alfonso ER, De Gregorio MA, Mateo P, et al. Radiation myelopathy in over-irradiated patients: MR imaging findings. Eur Radiol 1997; 7:400-04 CrossRef Medline

17. Koehler PJ, Verbiest H, Jager J, et al. Delayed radiation myelopathy: serial MR-imaging and pathology. Clin Neurol Neurosurg 1996;98: 197-201 CrossRef Medline

18. Wang PY, Shen WC, Jan JS: MR imaging in radiation myelopathy. AJNR Am J Neuroradiol 1992;13:1049-55; discussion 1056-58 Medline

19. Melki PS, Halimi P, Wibault P, et al. MRI in chronic progressive radiation myelopathy. J Comput Assist Tomogr 1994;18:1-6 CrossRef Medline

20. Hopewell JW. Late radiation damage to the central nervous system: a radiobiological interpretation. Neuropathol Appl Neurobiol 1979; 5:329-43 CrossRef Medline
21. Farrell BT, Hamilton BE, Dósa E, et al. Using iron oxide nanoparticles to diagnose CNS inflammatory diseases and PCNSL. Neurology 2013;81:256-63 CrossRef Medline

22. Rubin P, Johnston CJ, Williams JP, et al. A perpetual cascade of cytokines postirradiation leads to pulmonary fibrosis. Int J Radiat Oncol Biol Phys 1995;33:99-109 CrossRef Medline

23. Carmona R, Pritz J, Bydder M, et al. Fat composition changes in bone marrow during chemotherapy and radiation therapy. Int $J$ Radiat Oncol Biol Phys 2014;90:155-63 CrossRef Medline

24. Goertz O, Poettgen C, Akbari A, et al. New model for long-term investigations of cutaneous microcirculatory and inflammatory changes following irradiation. J Radiat Res 2015;56:456-61 CrossRef Medline

25. Wong CS, Fehlings MG, Sahgal A. Pathobiology of radiation myelopathy and strategies to mitigate injury. Spinal Cord 2015;53: 574-80 CrossRef Medline

26. Feldmeier JJ, Lange JD, Cox SD, et al. Hyperbaric oxygen as prophylaxis or treatment for radiation myelitis. Undersea Hyperb Med 1993;20:249-55 Medline

27. Chamberlain MC, Eaton KD, Fink J. Radiation-induced myelopathy: treatment with bevacizumab. Arch Neurol 2011;68:1608-09 CrossRef Medline

28. Schultheiss TE, Kun LE, Ang KK, et al. Radiation response of the central nervous system. Int J Radiat Oncol Biol Phys 1995;31:1093112 CrossRef Medline

29. Coderre JA, Morris GM, Micca PL, et al. Late effects of radiation on the central nervous system: role of vascular endothelial damage and glial stem cell survival. Radiat Res 2006;166:495-503 CrossRef Medline

30. Okada S, Okeda R. Pathology of radiation myelopathy. Neuropathology 2001;21:247-65 CrossRef Medline

31. Burns RJ, Jones AN, Robertson JS. Pathology of radiation myelopathy. J Neurol Neurosurg Psychiatry 1972;35:888-98 CrossRef Medline

32. Lu FG, Wong CS. Radiation-induced apoptosis of oligodendrocytes and its association with increased ceramide and down-regulated protein kinase B/Akt activity. Int J Radiat Biol 2004;80:39-51 CrossRef Medline

33. Seddon BM, Cassoni AM, Galloway MJ, et al. Fatal radiation myelopathy after high-dose busulfan and melphalan chemotherapy and radiotherapy for Ewing's sarcoma: a review of the literature and implications for practice. Clin Oncol 2005;17:385-90 CrossRef

34. Rubin P. The Franz Buschke lecture: late effects of chemotherapy and radiation therapy: a new hypothesis. Int J Radiat Oncol Biol Phys 1984;10:5-34 Medline

35. Chao MW, Wirth A, Ryan G, et al. Radiation myelopathy following transplantation and radiotherapy for non-Hodgkin's lymphoma. Int J Radiat Oncol Biol Phys 1998;41:1057-61 CrossRef Medline 